\title{
Discursive mélange and multiple dilemmas: navigating New South Wales 'special' education policymaking
}

\author{
Jessica Chong \\ College of Education, Charles Darwin University \\ jessica.chong@cdu.edu.au
}

Keywords: inclusive education; education policy; neo-liberalism; New South Wales

\begin{abstract}
The article is aimed at deconstructing the complexities involved in the process of 'special' education policymaking in New South Wales (NSW) with a focus on departmental challenges and the dynamics of external influences. Rather than full inclusion, the NSW government has maintained a strong policy position endorsing a continuum of support services to achieve middle ground among differential parental demands. The multiple dilemmas circle around dissimilar views and preferences of various stakeholders, consequentially giving rise to a rich hybrid of 'special' education discourses in NSW evolving from integration, inclusion to diversity. The Australian government has persistently supported school marketization and a strategic performance-based reward system that has widened the social divide instead of mitigating the influence of student's background on educational outcomes. The cascade of accountability induced by the federal competitive agenda has aligned the NSW Government and its schools to bid for greater academic excellence while inclusion and equity are inadvertently sidelined in policy agenda.
\end{abstract}

\section{Introduction}

In the Australian federation of six states and two territories, New South Wales (NSW) comprises one-third of the country's population as the largest state with over 7.5 million people. Australia practises a system of parliamentary democracy and the responsibility for K-12 schooling from pre-school until Year 12 rests with individual States and Territories as stated in their respective constitutions. Federalism has enabled policy diversity and innovative measures across different states, resulting in considerable variation in student support structures. Although NSW has the lowest poverty rate of all Australian states $(9.8 \%)$, a high level of social disadvantage, unemployment and crime rate concentrates in certain communities around the metropolitan and remote rural areas. The Household Expenditure Survey (HES) reveals a higher risk of hardship and poverty among households with disability (ABS, 2017b). Such deprivation extends to the Indigenous communities and it is particularly pertinent to NSW in which $33 \%$ of the total Aboriginal population in Australia resides (ABS, 2017a). The disproportionate representation of Indigenous students in 'special' schools and classes, and the 53\% dropout rate of Indigenous groups from Year 7 to 12 have come under the spotlight (Graham, 2012).These statistics reflect the high incidence of additional needs which NSW has to deal with and education is one of the most useful tools to break the cycle of poverty among children from disadvantaged backgrounds and with a disability (Afzal et al., 2012).

The article is aimed at deconstructing the complexities involved in the process of additional learning support provision or more formally known as 'special' education policymaking in NSW, with a focus on departmental challenges and the dynamics of external influences including federalism and stakeholders' demands. While other prominent literatures have touched on the trends in NSW support provision (Dempsey, Foreman, \& Jenkinson, 2002; Graham \& Sweller, 2011; Graham, Sweller, \& Van Bergen, 2010), it is also important to build on those findings to substantiate how the local socio-political context and globally influential discourses affect the makings of these services. Discourses can bring about powerful effects as the composite political ideals, economic principles and socio-cultural values travel 
through the global space and influence education policymaking. Dale (2005) refers to the complex interactions between national education systems and these supranational influences as 'the pluri-scalar nature of education governance' (p. 117), where special education regulations, funding mechanism and support provision are influenced by a broad set of agents including state, market, family and community.

Educational policymaking has also become the intersection point between inclusion and neo-liberalism. Hursh (2005) describes some of the characteristic elements of neo-liberal influence on educational policies and practices, including the expansion of standardised testing, accountability measures, institutional competition, school choice, managerialism, performative steering and curricula fundamentalism. Inclusion is quite the reverse, requiring active governmental input, which is described as a process of 'addressing and responding to the diversity of needs of all learners' as well as 'reducing exclusion from education' (UNESCO, 2005, p. 13). The inclusion movement argues for the reconceptualisation of schooling in order to break down the concept of the "special" and "regular" school or classroom so that the provision of effective individualised support meets the diverse needs of all learners through the provision of meaningful differentiated curriculum, effective teaching, and necessary support (Graham, 2006; Slee, 2011). Conversely, special education conceptualises difficulties in learning as arising from deficits in the neurological or psychological make-up of a child, which is analogous to an illness or medical condition (Skidmore, 2004). Graham and Jahnukainen (2011) argue that inclusive education is difficult in gaining traction because of the attractions that special education holds for general education policy. Special education has been misused as an attractive solution to the inability of general education in dealing with the learning problems of at-risk students. Low-performing students who fail to conform due to various socio-emotional, physical or intellectual difficulties are segregated to save schools from the additional distraction, stress and required human resource. This "productive" mode of school governance in support of special education is more compatible with neo-liberal approaches to organisational management than the philosophy of inclusive schooling endorsed by UNESCO. Thus, education provision can be increasingly fragmented as the academic pressure imposed on students and the accountability for results experienced by schools increase along with the promotion of competition within and between schools based on neo-liberal outcome-based governance. Chong (2018) highlights the importance of an inclusive education system which prioritises the intellectual, social and learning needs of the children above other performative, selective or cost-saving agenda, however the conflicting elements of the two discourses have contributed to a difficult policymaking sphere.

This paper thus examines some of the challenges that can be observed when the global call for more inclusion on the one hand and neo-liberal reform on the other hand pervades the sphere of NSW educational policymaking. What effects are produced by the intensifying competitive climate to higher literacy and numeracy attainment and school marketisation?

\section{Methods}

The 'Russian doll' approach (Chong \& Graham, 2014) was employed within the author's three-year doctoral research to examine the challenges involved in policy designs and the development of coping strategies through the lens of experienced policymakers. The nested model involves the examination of discursive influence, policy development and interview data by contemplating the influences from the wider socioeconomic and politico-cultural context at the macro level, analyzing discourses embedded in policy documents at the meso level, and triangulating those trends with the policymakers' insights at the micro level. To enable a deeper view into real-time thought processes, five key policymakers from the NSW Department of Education (DoE) ${ }^{1}$ as indicated in Table 1 were interviewed for $40-90$ minutes to comment on (a) the range of learning support services available and which of these the policymakers supported and why; (b) arising trends and challenges associated with the effort to promote inclusion; (c) the impact of neo-liberal agenda on education policymaking and (d) future direction of support provision.

1 After the research was completed, the Department of Education and Communities (DEC) has been renamed as the Department of Education (DoE) in July 2015. For consistency, DoE is used in the article. 
Table 1. New South Wales interview participant codes

\begin{tabular}{|l|l|}
\hline Participant Codes & Unit (Department of Education) \\
\hline N1 & Office of the Director-General \\
\hline N2 & Disability Programs Directorate \\
\hline N3 & Disability Programs Directorate \\
\hline N4 & Planning and Innovation \\
\hline N5 & Student Engagement, Evaluation Bureau \\
\hline
\end{tabular}

Critical analysis of the interview data was based on Strauss and Corbin's grounded theory approach (1990) which involves manual categorisation, coding and interpretation of data sets. As Yin (1994) maintains that "data analysis consists of examining, categorizing, tabulating, or otherwise recombining the evidence to address the initial propositions of a study" (p. 99); identification of themes was conducted through multiple readings of raw data and also based on the research topic to determine emerging categories. Themes were then analysed to determine their pervasiveness across different academic texts and participants (Talja, 1999). After this, cutting and sorting ensued by grouping together answers from different participants and relevant supporting information from policy texts and other research reports. The merging of interview data and primary sources had the value of generating triangulation for each dataset. The emerging themes were then pieced together and narrated in three sections to form a comprehensive picture of the inquiry, with interview quotes inserted where appropriate to enhance data interpretation. Three main themes are identified from the interviews which are contextualized in pertinent policy development and discursive trends as based on the "Russian doll" approach; together they form the backbone of the article as detailed in the following sections which discuss actual challenges faced by NSW policymakers in the domain of learning support management and the ensuing resolution processes.

\section{Emerging trends: counteracting diagnosis as a funding leverage}

Eligibility for NSW special education support principally relies on the diagnostic procedure of determining students' primary needs in one of the disability criteria (language disorder, physical disability, intellectual disability, vision impairment, hearing impairment, mental health problems or autism) to gain access to additional funding support (NSW DET, 2003). To some extent, the NSW learning support or "special" education system is still anchored in the psycho-medical paradigm with paediatrician, child psychiatrist and school psychologist or counsellor acting as the gate-keepers to ring fence specialist services based on specific assessment processes to diagnose a disability (Autism Awareness, 2018; Powazuk, 2013). While Tearle and Spandagou (2012) point out that NSW education policies are saturated with the deficit discourse characterizing the medical model, the government rationalizes that such funding mechanism ensures transparency of allocation to areas of greatest needs or those with the most significant disabilities (NSW Government, 2011b). In addition, special consideration is given in cases where a student's disability does not fit neatly into the prescribed Disability Criteria; a range of education options is also provided including mainstream, integrated and segregated settings (NSW Government, 2011b). Categorical resource allocation enables the provision of individually targeted funding but can also act as a 'perverse incentive' to pin a disability category on students with learning difficulties.

The funding support mechanism - individualised funding - is predicated on a diagnosis: you've got to fit one of seven boxes. There are thousands of kids that have got their support contingent on that. It generates a dollar value, first and foremost, for the kid. For the school. And what does that dollar value invariably buy? A minder to take the kid away from the classroom teacher. So that becomes the trigger. (N3)

The discussion with the policymakers occurred prior to the adoption of Every Student Every School (ESES) and was instrumental in capturing their concerns in relation to the adverse effects of disability diagnosis. Prior to ESES, two funding policies introduced by the DoE are potentially conducive to the development of inclusive education - Funding Support and Learning Assistance Program. Funding Support has

2 The title Director-General was changed to Secretary in July 2015. 
financed educational provisions for children diagnosed with a disability in regular classes since the mid 90s. The Learning Assistance Program (LAP) launched in 2004 drew in annual federal grants through a census-based formula to fund educational support provision for students with low support needs in basic areas of learning without the requirement of a disability confirmation (NSW Government, 2011b). Schools were entrusted with the responsibility of making optimal use of the LAP funds to obtain "training and development, additional teacher time, teachers' aide (special) time, teacher release, transfer of duty and program coordination time" (NSW DoE, 2018) for students with mild disabilities and learning difficulties in the mainstream classrooms. Despite these positive efforts, inclusive school culture has not been successfully cultivated as diagnosis-based funding support has shown to be a much more popular choice than the needs-oriented LAP (Graham \& Jahnukainen, 2011). As disability exists in a continuum, from mild, moderate to more complex or severe, stakeholders tend to undertake relevant measures to push for a confirmed disability in order for a student to be recognised as having higher support needs to gain access to the individually targeted Integration Funding Support. The initiatives to reduce disability diagnosis through such in-school remedial support has failed to be met as Graham and Jahnukainen (2011) revealed an upward trend for recipients of Funding Support but a downward trend for the LAP.

We give you the money but you've got to make a decision about the money (LAP). That's much harder than 'Oh, this kid looks different, let's go and get him diagnosed so I can get a thousand dollars and so another thousand dollars' (Funding support). (N3)

N3 from the Disability Programs Directorate spoke of the flat-lining trend of 'hard disability types' over time, yet the diagnosis of autism spectrum and mental health disorders in NSW had massively escalated in recent years. He revealed that the detection of visible physical, vision and hearing impairments was generally more objective, whereas subjective types of additional needs such as behaviour disorder, autism and emotional disturbance were much harder to confirm as 'different standards applied subjectively, and the implications could be very different on the child'. While the proliferation of diagnosis was partly explained by the improvements in medical science, 'hidden' disabilities such as neuro-sensory issues increasingly grow as areas of greatest needs.

Most of the kids that we are now supporting today... during their prenatal periods and then into early life, they've got hidden disabilities. They don't emerge until developmental milestones move on and they don't reach them. Mental health disorders, those sorts of things that you know you can question whether they're there or they're not... So our graphs would regularly look like peaking for mental health and autism, spiking, but then the others would be tailoring away. (N3)

N3 from the Disability Programs Directorate shared that an aberrant spike was detected at the departmental level when a new autism class is set up in the region of Riverina every three months. Closer investigation revealed that a school in particular had $40 \%$ of children identified with autism due to the intervention of a new medical practitioner 'and the clinic would result in all this' (N3)! N3 further explained that schools are inclined to bid for disability confirmation which opened up a broader range of educational options for a child. Consequently, N1 detailed that linking disabilities with a dollar value had led to the uprising trend of 'desirable diagnoses'.

Funding increase to education support goes hand in hand with the growing disability diagnosis and special education enrolment. From 1998 to 2011, official statistics by the NSW Government have revealed a significant $62 \%$ growth in the percentage of students receiving support provisions from $3.7 \%$ to $6.0 \%$ (NSW Government, 2011a), the latest data from 2016 reveals continuous increase. As shown in the graph below, support class placements and funding support provision in regular classes escalate at an even higher rate ${ }^{3}$. Students with autism or emotional disorders have disproportionately occupied the expanding support classes and special schools are increasingly accepting students identified with behavioural problems (Graham \& Sweller, 2011). While the number of students with vision, hearing or physical impairments remains static, a noticeable climb is seen in the enrolment rate of students in the categories of behaviour disorder which has grown by $585 \%$, followed by emotional disturbance $(348 \%)$

3 Annual funding and enrolment data for all placements are unavailable from 2011 onwards from the DEC official website. 
and autism $(280 \%)^{4}$. Other trends include the huge discrepancy in disability rates between boys and girls where $77 \%$ of special school enrolments are male (AISNSW Institute, 2017) and the disproportionate over-representation of Indigenous students in special education (Graham, 2012). With the categorical resource distribution structure, the choice patterns for mental health diagnosis within the two categories of cognitive and social/emotional difficulties were especially prevalent compared to physical or sensory disability (AISNSW, 2017), yet the government lacked the mechanisms to avoid those practices. In fact, there has not been an influx of children from segregated settings into support classes and regular classrooms but the reversal.

Figure 1. Enrolment percentage of students with a confirmed disability in different educational settings within NSW government schools, $2005-2016$

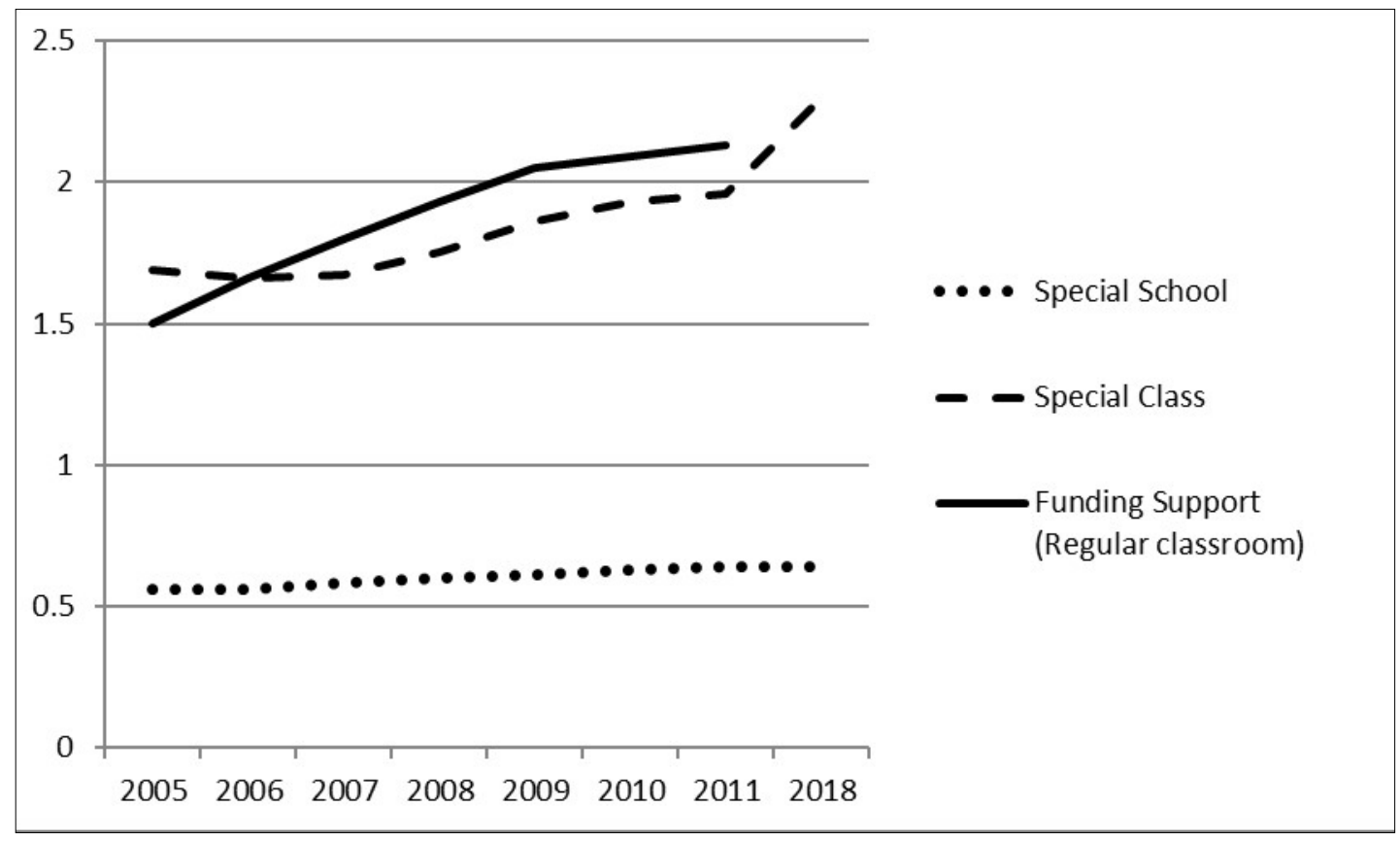

Source: NSW Government, 2005-2011; 2011a, p. 5; 2016

The NSW parliamentary inquiry was tasked with evaluating the education of students with a disability or special needs in 2017 which resulted in the release of 39 recommendations, however not without some discrepancies. The report advocates to have the presumption of mainstreaming formalised, where all students should be educated along their peers regardless of any differences or disabilities, unless such arrangement is proven unbeneficial. Yet, the paradox lies in the simultaneous proposition for establishing more segregated support classes, in addition to its already rising numbers of late that is much higher than the NSW enrolment growth (NSW Parliament Legislative Council, 2017). Such trend is reported by AAIE (2018) to have occurred to satisfy parental demand for support classes but fails to mask the underlying causes, namely parents' lack of awareness of rights to inclusive education, unclear specifications of what constitute reasonable adjustments and consequently unsatisfactory learning support provision in mainstream settings, challenges in securing essential funding support due to the narrow focus on disability criteria, discriminatory school culture in a competitive milieu, and the lack of support and training for teachers.

Thus, N3 affirmed that decoupling disability assessment from resourcing is crucial to 'avoid a national voucher scheme for disability based on individual kids, because the minute we do that, you've drawn a line around a group of kids and excluded a whole lot more' (N3). Those issues expressed by the policymakers required a new strategy to detach the earmark of government funds with every identified learning difficulty. The replacement of LAP with Every Student, Every School comes at an opportune

$4 \quad$ In the 2016 NSW enrolment figures in support classes and schools for specific purposes, highest numbers are found in the category of mild intellectual disability $(5,054)$, to moderate to severe intellectual disability $(6,200)$, autism $(2,285)$, emotional disturbance $(1,794)$ and behaviour disorder $(562)$. 
time that prevents the attraction of diagnosis for extra school funding through a fixed eligibility threshold of $\$ 6000$ to curb the surge of disability diagnoses in the vast grey area between serious and mild mental health disorders. Only students requiring educational support subsistence beyond the stated amount are eligible for integration support or disability funding as determined by a paediatrician, child psychiatrist, school psychologist and/or the schools' multidisciplinary team. In addition, the intensified focus on professional teacher training and the supply of more specialist teachers as well as teacher aides to over 400 schools are aimed at improving the education of children with disabilities in regular schools to fulfil the Commonwealth Disability Standards for Education 2005. The government thus disburses more funds for schools which are located in a community with higher prevalence of disabilities as well as those at the bottom $10 \%$ of NAPLAN ${ }^{5}$ ranking in students' learning outcomes. This new funding formula has resulted in a change of the amount each school receives, which could be an increase of financial assistance to small schools in rural localities while larger schools might see a reduction (Forbes, 2012).

In particular, the learning support specialist teachers serve as an easily accessible and useful source of pedagogic advice, consultation and collaborative teaching (NSW Government, 2011b). Distribution of such expertise in individual schools enables effective day-by-day engagement as opposed to a 'flyin fly-out 3rd day in July' awareness programme which N3 described as a futile effort due to the active turnover of staff. The NSW funding support model based on the disability criteria is rationalised by the policymakers as a fair and standardised means of leveraging funding for students with the highest support needs; the subsequent addition of ESES attempts to encourage school-wide support distribution. This resonates with the rich blend of discourses in NSW educational policies detailed in the following sections as reactions and coping strategies to the dilemmas sprung from public demands and federal neoliberal framework, serving as real-time examples of the dynamic problem-solving and appeasement nature of policymaking.

\section{A hybrid discourse: dilemmas of opposing demands and inner 'battles'}

Even though Australia has adopted the Salamanca Statement (UNESCO, 1994), the emphasis on inclusion has taken a back seat as the 2006 performance audit revealed that the NSW Government had not expressed a lucid stance in clarifying 'the relative merits of enrolment in a regular class versus enrolment in a special class' (AONSW, 2006, p. 9). A lack of clear endorsement for inclusion persists to date as the NSW Parliament Legislative Council report (2017) discusses at length the need to maintain varied educational settings, particularly in establishing more support classes although the number of support units which function as isolated "mini-schools" within mainstream school premises should be curbed.

The movement towards the integration of students with a disability commenced in the 1970 s and led to a dramatic increase in the enrolment of students with a disability in state-run mainstream schools. When the enrolment in government special schools dropped by 30\% in the period from 1986 to 1994 (Dempsey \& Foreman, 1997), it was believed that the call for educational placements in regular neighbourhood schools by the 1988 Special Education Policy and the 1993 NSW Disability Services Act had paid off. However, McRae (1996) reported that 'surrogate special schools' (p. 23) in the form of segregated support classes in regular schools had mushroomed since 1986 which more accurately explained the initial decline. Although increased integration had occurred, inclusion had not. The downward trend in special school enrolments had taken a turn since 1999 and has gradually climbed up to $0.6 \%$ of total student population. This figure has been rather stable since 2005 and constitutes $14 \%$ of the special education student cohort in 2011. The increase occurred despite a 3.5\% decrease in government school enrolments from 1997 to 2007. The number of support classes continues to grow ever since while special school enrolments are relatively constant (NSW Parliament Legislative Council report, 2017).

The DoE endorses the recognition of diverse needs through the maintenance of a continuum of services with the rationale that a governmental body carries a duty to a feasible extent in fulfilling requests from the general public, and to achieve middle ground amidst challenging demands. N2 from the Disability Programs Directorate reasoned that intense advocacy by parent lobbyists and political groups for regular

5 The National Assessment Program - Literacy and Numeracy (NAPLAN) is another Commonwealth initiative which sets learning benchmarks through a nationally standardised assessment format. 
schools to accommodate children with additional needs has been concurrently conflicted by opposing calls for more support classes and special schools. If the Government remains committed to the single philosophy of inclusion and dictates mainstream placements, some groups would be displeased, thus a more flexible policy position is adopted to provide what is in demand. Whereas some parents residing in metropolitan areas have a greater variety of choice in electing regular, special class or special school, this range is more limited in regional areas.

We're beaten up by people that say, 'We want support classes.' We're beaten up by another group saying, 'Why are you still establishing support classes, because we don't believe that you should be!' That's a dilemma, because I guess that is a policy position. 'Well, that is what we are trying to be - all things to all people.' They're almost exact opposites, the government's policy is that it's about the parents being able to choose what they would like. (N2)

However, 80 support classes catering for students with mild intellectual disability have been closed which has drawn some negative reactions due to increased enrolments of students with multiple disabilities in the remaining support classes (PSPF, 2009). In response, the government states a need to optimise the use of special education services to ensure financial viability (NSW Government, 2011b). The Government is also wary that inclusion might 'submerge' some children with a more urgent need for support when they become 'lost within the broader community' (N1). Inclusion in the mainstream classroom is only viable provided that the learning needs of the children are appropriately addressed.

If the poor children are so very, very, very disabled with a really extreme disability, and need to be in a special place, make sure that all the values and principles you'd expect in a school are flourishing there. Make sure that their needs and interests are catered for... but don't pretend these kids don't have difficulties. (N1)

Full inclusion, by having all students taught in the mainstream classrooms, is thus not the aspiration of the Department as opposed to instilling an inclusive school culture along the 'normalization continuum' (N2). It becomes incumbent on the school principal to ensure that inclusive practices are well-implemented, even in special education settings such as special schools and support classes. N3 stressed the importance of providing children with meaningful age-appropriate learning experiences. A student with moderate intellectual disability should not participate 'in a Year Nine lesson doing Shakespeare because everybody else that's 15 is engaged in this thing called Shakespeare'. The Department's Curriculum Planning, Programming, Assessing and Reporting K-12 policy allows curriculum modification in the form of an adjusted personalised education programs which might aim for similar or different learning outcomes based on individual needs, strengths, goals and interests in order to make learning more inclusive and dignified (NSW Government, 2011b).

Yet, government special schools and support classes increasingly cater for students with emotional and behavioural disorders. The training of self-management skills for these children is not necessarily better when provided in segregated settings. Conversely, N2 pointed out that non-compliant students tend to be removed from classrooms so that lessons could carry on without disruptions, as more power has been handed to the then Director-General, or currently known as the Secretary, in transferring students with 'potential and/or demonstrated violent behaviour' to segregated settings (NSW DET, 2010, p. 1). In addition, segregative practices have persisted in some integrated support units which reinforce the stigma of disability and abnormality within schools, with more cases documented in the NSW Parliament Legislative Council (2017).

The way the kids in the support unit are being treated is just awful, and what this parent was saying, 'Now, this is actually really, really damaging for everyone in this environment.' She said, 'Those kids in the support unit were actually better (off) in a special school.' Her concern is that it's more damaging for the kids in a regular class to see the way these other people with disabilities are being treated. So if it's not done well, then you're actually strengthening that stereotype that they're weirdos...because they had this new outdoor area built and the message was: if kids from the special unit are in there, you're not allowed in there. (N2) 
The policymakers interviewed for this research believed that to some extent diagnosis had been used to absolve some teachers of their inability to teach students effectively, although this is not intended as a generalisation as conversely there are outstanding practices and supportive teachers across NSW schools. Instead of evaluating ways to deliver instruction that is better adapted to the learners' needs, there is still a tendency for some teachers and other professionals to view a challenging learning situation as a result of students' neurological deficit. The 2010 Parliamentary Inquiry launched by the NSW Legislative Council into the education provision for students with a disability or special needs has disclosed the mindsets of some schools which opt for diagnosis and labelling rather than capacity building and professional development to cope with students' learning difficulties (NSW Parliament, 2010). The expert advisory panel formed to advise the Government around supporting children with learning difficulties also confidently highlights that students' academic incompetence is a product of poor teaching. While some children might be able to survive poor instruction, a huge number remain illiterate because the lessons fail to take into account their learning needs. The focus seems to be on 'getting rid of the kid' (N2) through suspension and expulsion even in many cases where behavioural issues actually stem from a disability (PWD, 2010), and schools rarely reflect on the situation thereafter 'because the problem's gone'. N3 shared that there is a great variation across NSW schools in the quality of education and advice provided to local communities and the Department is aware that the NSW education system still lacks efficient intervention procedures and a strong network of support to prevent school failure and discriminatory practices.

More informed parents and communities will demand a different type of service to less informed communities. There can be an opportunity for school principals in particular to be bullies of local community parents, in terms of taking advantage of the fact that these people might not be informed, teaching upon them what they think might be or might not be good for their kid. (N3)

The following quote shows that there is also a tendency to profile a child with a disconnected list of needs according to the eligible sources of support which scatters rather than assembles related services for holistic support provision. Determining the primary disability for funding income is equally problematic as it is often the combination of a few learning needs that makes a unique support requirement. 'Should this kid go into an autism class or an IO class (for moderate intellectual impairment)?' This question posed by N2 reveals many dilemmas within educational decision-making and thus the Department had been deliberating a solution to such dispersed way of needs identification and support provision. Schools need to work closely with parents to consolidate the support a child needs especially as illustrated by N3 below:

If an Aboriginal kid has a non-English speaking background, comes from a low socioeconomic home and is deaf, but is gifted and talented! We fund the child's Aboriginality, non-English speaking background and low-socioeconomic needs, disability and giftedness all separately. The resources all sort of trickle in like little streams into a pot, but the school doesn't look at it in a holistic way.

A functional assessment tool, currently known as the Personalised Learning and Support Signposting Tool (PLASST), has been under trial which involves teachers working with parents to profile a child based on 46 items for evaluating and documenting students' needs in various school-related practical tasks (NSW DEC, 2012). The tool responds to the call from public schools principals that the NSW education system lacks mechanisms to determine the impact students' disabilities have on their overall learning efficiency, notably in viewing the combined needs arising from multiple disabilities (PSPF, 2009). This form of support assessment employs a broader, individualised and holistic approach to evaluating learning needs that covers communication, writing, reading and socio-emotional aspects although it is not meant for funding allocation. Clearer specification of assessment criteria also compensates for the many non-normative or objective medical categories of the previous LAP model and the detachment of mild support requirements and funding has the potential to curb the trend of over-diagnosis. Since funding is not tied to the functional assessment, thus any child can be functionally profiled to demonstrate their learning needs so that available resources can be effectively sought within the school or drawn from external help. Besides reducing bureaucracy and enhancing school-level efficiency, students who 
previously failed to meet the compartmentalised disability criteria could benefit from the allocation of support. The tool is also able to show the integrated strengths and weaknesses of a child so that schools could holistically provide appropriate modifications.

While PLASST is promising as the functional assessment tool to profile learning needs more holistically, yet it is perceived to be inferior in terms of acting as a lever to attract substantial funds relative to having a firm diagnosis of disability. Medical evidence of a diagnosed disability remains a key consideration for individualised targeted funding. The parliamentary report conducted by NSW Ombudsman (2013) also highlights that public schools have much lower applications or access request filed for disability provisions compared to private schools. Further investigation reveals a complicated mesh of factors. Private schools are more proactive in garnering additional funding to satisfy the parents as customers in greater support provision whereas many underprivileged students in public schools come from less educated and poorly-resourced families without the means to consult a doctor for disability certification. In addition, low academic expectations from these students contribute to a lack of effort from school personnel in applying for disability provisions (NSW Ombudsman, 2013).

In order to improve co-ordination during policy planning and implementation, the Working Together strategy (NSW DoE, 2017) has been introduced within and between all directorates, as well as with parents, government agencies and non-government providers, in order to function as an effective organization. According to $\mathrm{N} 1$, issues relating to children with a disability are often indiscriminately referred to the Disability Program Consultant without prior judgment on the other curricular, health or social needs involved, as his or her disability is presumed to be the cause. The attitude of indifference is prevalent in the department when such responsibilities should fall on all educators and policymakers instead of compartmentalising their needs to the 'special' workforce. The 'battles' that exist between policy representatives from different directorates spring from a lack of understanding of the integrated function in educational service provision.

So if there's an issue in the school, and it just so happens that it involves a young person with a disability; 'Oh, you better ring the Disability Program Consultant.' Now, even though it might be health care issue, or a curriculum issue, no, it's straight to...so the focus is on the child's disability, not on: what's the actual underlying issue here? 'Oh, that person's special, so there must be special people who look after those!' (N2)

Ultimately, this strategy strived to instil the same level of understanding with regard to policy rationale, implementation needs and educational goals across all stakeholders, as opposed to having different attitudes and beliefs especially around disability issues. Embracing and effectively coping with student diversity as a common goal must penetrate all levels of the education system to gain traction. The policymaker explained that even with reasonable policies put in place, often results were not delivered at the implementation phase due to the loose connection and communication between stakeholders. N5 also shared a similar concern that policy process often came from higher authority through the request of information from various directorates and offices but feedback and decisions were seldom relayed back. Multidisciplinary collaboration has to be enhanced in NSW schools and the Department of Education and Training to jointly respond to different aspects of a child's needs in an integrated manner. The multiple dilemmas circle around dissimilar views and preferences of various stakeholders, consequently giving rise to a rich hybrid of education discourses in NSW evolving from integration to inclusion to responses to diversity (Graham \& Jahnukainen, 2011). The neo-liberal discourse predominating the political environment further adds to such complexity when NSW is subjected to federal influences which transmit through to the workings of the Department and schools.

\section{The impetus of neo-liberalism under federal influence}

At the time the [Federal] Labor government came in, they had a sort of manifesto of policies, they did stick to their guns election cycle after election cycle. They said they wanted fairer school information, and they pushed that through annual school reports, assessment programs, developing and enhancing external tests and examinations. Within 
the department, I think there's a very strong political influence - well, I can see this as plain as day - that the Commonwealth Public Service and the public service in some other jurisdictions is far less influenced by government than it is in NSW. (N5)

The NSW policymaking process has been linked with the former federal Labor government's priorities to use results-based governance which has intensified since 2000 with funding being directed for 'major enhancements relating to increased testing and performance measurement' (DET, 2000, p. 15) and reporting to the parent-clients. While the Programme of International Student Assessment (PISA) only affected schools indirectly in the first few cycles of assessments, N3 asserted that it has now featured in day-to-day decision-making in NSW very prominently. Since the year 2000, PISA has ranked reading, mathematical and scientific skills performance of 15 year old students in participating countries and has thus provided education policymakers with an additional point of reference when reviewing domestic policies and programs. Given that NSW major agendas have always lingered on 'attainment, retention, university outcomes and the Bradley targets' (N4), NSW's consistent ranking slippage in all three domains between 2000 and 2009 as well as the declining percentage rate of upper level PISA performance, which is much faster than the expanding tail, have generated serious concerns among policymakers even though Australian performance is above OECD average.

The slight slip at the upper scales of Australian students' reading proficiency level is explained by N1 as the side effects of overemphasising basic literacy skills to the neglect of higher literacy skills. The PISA results have also raised concerns relating to the different quality standards between schools, as N5 mentioned 'we've got some wonderful schools and some really struggling suburbs, but that just speaks to the complexity of the system'. Albeit 'high expectations' and 'closing the gaps' (DET, 2011, p. 8) are both targeted goals of the NSW policymakers, the focus on expanding the top two achievement bands for literacy and numeracy through NAPLAN is apparent, with the aim of securing $10 \%$ of total student population in those bands by 2012 and $12 \%$ by 2016 (DET, 2007; 2009; 2010). Students also faced greater pressure to conform to 'a standards framework of skills bands' from as early as 1997 (DET, 1997, p. 5) which have expanded through the federal implementation of the Smarter Schools National Partnerships, 'making attainment as an agenda, front and centre, for us' (N4)! A reward system is in place to financially recompense beneficiary states which succeed in reaching the targeted benchmark. Local and nationally-agreed literacy and numeracy targets have been established which transcend the public sector to include Catholic and independent schools.

Priorities to support educational consumerism have not changed since the Liberal Party took over in 2013. In addition, the Gonski needs-based schools funding model (Australian Government, 2011) which was well under way to channel resources to disadvantaged students faces funding cuts in its last two years of implementation under the Liberal leadership, showing a lack of their commitment to reduce educational inequality (Dziedzic et al., 2016). A second review was undertaken in 2017 which has resulted in the publication of another review report (Australian Government, 2018) with emphasis on performance monitoring and curricular improvement, also known as the Gonski 2.0. Despite private schools being earmarked for budget cuts under the Gonski 2.0 funding deal, increased funding for private schools is again witnessed this year due to interim bonus fund arranged by the federal government to ease them through such transition, which has invited strong backlash from the public (McGowan, 2018). While the federal government rationalizes that more funding does not guarantee better results, the breach of commitment contradicts the sustaining flow of Commonwealth funds to non-government schools.

Policy intention and end products can often be contradictory. Neo-liberal governance bears an opposite effect to that of inclusion, preventing inclusion policies from exercising a more lasting influence in the school system. The standards-based curriculum framework with an outcome-based approach has not taken into account the whole broad cohort of school children even though the Department has the duty to 'cater for the top and bottom cognitively' (N1). N5 also commented that the focus of classroom teaching is increasingly narrowed down to the areas scoped in standardised examinations so that all students could become 'test-savvy' by the time they sit for Year 12 High School Certificate. The culture of performativity which has infiltrated the NSW education system has also added to the widening achievement disparity. The public policy of information transparency and comprehensive reporting of school performance have been taken to a new height with the publication of school performance aggregates on the My School website. As a federal initiative, the emphasis on literacy and numeracy benchmarks in the National 
Assessment Program - Literacy and Numeracy (NAPLAN), with the comparison of like-schools results on the My School website, has contributed to increasingly heavy academic demands and superficial learning in schools (Polesel et al., 2012). Along with increased media coverage, My School has inadvertently become a resource for parental reference to compare performances when choosing schools. Lingard (2010) also underlines possible risk of the 'potential for the 'naming' and 'shaming' of poorly performing schools' (p.130) when the connection between disadvantaged socioeconomic background and student performance is masked behind online statistics which fail to highlight local efforts and the quality of teaching and learning.

When you look at NAPLAN data - remember, it's only one point in time. Two: It only assesses certain aspects of literacy and numeracy. Three: it's not meant to be a judge of the whole quality of schooling which goes on in the school. (N1)

Nevertheless, NSW policymakers conceive inclusion as increased participation of students with additional support needs in standardised tests such as NAPLAN (Graham, 2016). Compatible measures for this purpose include practical adjustments to test conditions and test preparation through drill exercises, although some argue that these inhibit rather than stimulate sustained meaningful learning (Luke, 2010; Polesel et al., 2012). The reporting of student performance at individual, school, regional and state levels in years $3,5,7$ and 9 has pitted students and schools against each other in competition for academic recognition and led to the accentuation of between-school differences. Information concluded from such aggregate level data to compare schools that are categorised under the same profile of low or high socioeconomic status is misleading as they are very dissimilar in terms of student population, locality and culture. Even though value-added components such as relative effective indicators of similar schools are incorporated into the performance analysis of NAPLAN, inclusive strategies and culture are not evaluated as part of the essentials of school effectiveness. Under the intense pressure of school comparison, the indignity of unachieved standards, low ranking and school ineffectiveness are degradingly associated with low-performing students who have additional needs or from disadvantaged background (Lingard, 2010). There are also reservations about the true diagnostic value of NAPLAN.

If you want to use it diagnostically, you don't sit the test in May and give them the results in August. [You'd] use it the next day, the next week. Or at least in the same month. (N4)

The effect of federal imposition on local state policies is evident. The obsession of standards and ranking in the current assessment scheme has a stifling effect on efforts to promote inclusion. Reports (Andersen, 2010; Bagshaw, 2016) have surfaced that schools request parents to keep their academically struggling children at home through formal exemption especially "on the basis of intellectual or functional disability or if they have been in Australia for less than twelve months and are from a non-English speaking background" (Gable \& Lingard, 2013). Such exemptions not only result in the lack of participation and assessment profiles of students with disabilities during NAPLAN tests but more adversely have affected the level of attention given by teachers during the intensive periods of test preparation from the practice of educational triage (Gillborn \& Youdell, 2000) as they are deemed lacking the potential of passing tests and raising school ranking (Hardy, 2013). Testing accommodations that are allowed under NAPLAN do not take into account the individualised learning goals of students with disabilities which are perceived as incomparable to national standards hence leading to their systematic exemption. Under the highly charged federal accountability atmosphere to meet performance targets, schools in NSW encounter enormous difficulty in fulfilling their inclusive responsibilities towards children behind their grade level of competency.

While high-performing selective and private schools emerge as the top choice in the educational market at one end, low-status schools in deprived neighbourhoods are left with a bad reputation from bottomranking educational performance. $\mathrm{N} 1$ brought up the issue of disproportionate representation of children from significantly disadvantaged areas and of Aboriginal origin in the lower achievement bands of PISA and NAPLAN, which could concentrate in a class or schools that only contained such 'remnant hard core' group. N4 was more concerned that those children would be perceived as 'that kid (that) dragged us down' in the presence of these high-stake testing. The effects are detrimental especially for students with additional support needs who become the victim of this ranking contest. 
The school might want that [enrolment] figure [of students with disabilities] to look large because maybe that will be a filter for interpreting that performance. However, there may be interest in that figure being smaller, because it makes your school look like, you know, I can send my child there and they're not going to be at risk of being in a class which will be diverted, or over-run, by these integrators. (N4)

The promotion of education as a marketplace has been taken up in NSW since the mid-1970s by directing state and federal funds to non-government schools. The era of comprehensive schools with strong social and ethnic integration through the 60 s and 70 s has given way to an exponential growth of private sector enrolment since 1978. Government-funded private providers now account for around a third of NSW schools which include 'low-fee Christian schools, ethno-linguistic schools, Catholic schools, as well as high-fee selective schools, against which public schools must now compete' (Vickers, 2004, p. 13; Private Schools Directory, 2018).

While learning support is one of the components of the productivity and social inclusion agenda in the Council of Australian Government, the private education sector and school performance assessment receive a much larger proportion of federal allocation. Under the National Partnerships, many of the listed equity programs are launched on a temporary basis without guaranteed continuation of support for the targeted students. Australia's current centre-right political climate is evidenced by the generous funding support to non-government schools which amounts to two-thirds of Commonwealth Government funding in the federal budget 2010/11 (Harrington, 2011). The inequitable budget allocation is inconsistent with the higher funding needs of public schools which educate around $67 \%$ of the nation's children (Bonnor \& Caro, 2007). The recurrent and growing financial support given to independent schools since 2001 based on the Socio-Economic Status (SES) funding model shows federal unwavering endorsement of the neo-liberal private economy. Independent schools are ironically overfunded from 100 to 250 per cent of the school resourcing standard (SRS) in contrast with NSW public schools which receive only 89 per cent of their SRS (Baker, 2018). Public schools have reported $\$ 13,318$ annual income per student compared to $\$ 20,053$ per student in private schools as a result of more than $40 \%$ of continuous rise in federal and state government funding since 2009 (Singhal, 2018). There is an ongoing vicious cycle at play which revolves around principals' moral obligation to enrol students with a disability in public schools while facing scarce funding and teachers' struggle to meet NAPLAN performance targets in these increasingly diverse classrooms (Taylor, 2017).

Nevertheless, this contrasts with the differing priorities of the NSW Government which disburses $92.7 \%$ of its annual education budget to public schools. While public schools face high levels of accountability pressure, huge amounts of public funding have been given to autonomous private schools with no accountability strings attached and no obligation to report spending efficiency and outcomes. Disability Advocacy NSW reported that $76.8 \%(90,000)$ of students with a disability attend public schools (Powazuk, 2013). A lack of individually targeted state funding for these students in private schools was argued to have created disincentives for enrolling parents as only a meager amount of Commonwealth grant is given upon application (NSW Government, 2011a). However, the NSW government asserts that students with disabilities in Independent schools in fact receive $80 \%$ higher funding through the bulk of Commonwealth provision, the lower private enrolment figure springs from the reluctance of private schools to accept these students so that resources are diverted to other fee-paying students without support needs (Cook, 2016; NSW Legislative Council, 2010). While a severe lack of funding for more than 2500 students with disabilities is a key issue highlighted in the Public Schools Principals Forum (2009), the NSW government claims that the huge investment for its specialist disability service system made through the Stronger Together 2006-2016 initiative has outshone financial input made by any other Australian State Government. The federal decision to financially support and politically promote the establishment of school markets has brought about segregative effect of education commercialism when higher SES students are able to pay for private education while children from poor families and with a disability make a default decision to attend the local public schools. The overrepresentation of low SES students and Aboriginal students in disadvantaged schools shows how school marketization can aggravate exclusion. N3 remarked that non-government schools by and large did not recognise the additional learning needs of children. Parents who had their children enrolled in non-government schools made use of the Centre for Effective Reading in Dalwood as a special education program because it serviced public and private schools. The complex political environment heavily influenced by the dominant neo-liberal approach 
to public administration at the national level has to a large extent restricted the 'manoeuvring space' (Broomhill, 2011, p. 137) available to the NSW Government as bound by strong federal obligation and financial relations.

Under the constant change of federal leadership accompanied by their differing commitments to disability provisions in education, the state of affairs remains laden with uncertainty but some directions are persistent: (1) Commonwealth funding in support of Australian non- government education providers persists while public schools remain as the main education provider for students who are socio-economically less privileged and/or with a disability (2) full inclusion is not envisioned in the NSW Education Department; a continuum of options remains the best policy to meet parents' or students' myriad needs (3) students with the highest level of need are prioritised to receive individualised funding while others are aimed to be supported either through school-wide allocation or by using the functional assessment tool.

\section{Conclusion}

The evolution of 'special' education policies in NSW reveals the problem-solution chain: Every Student, Every School was launched to cope with the failings of the Learning Assistance Program (NSW DET, 2006) and to deter over-diagnosis within schools to secure funding support; intra-departmental compartmentalised educational planning drives the need to implement the Working Together strategy for greater organizational efficiency; the functional assessment tool attempts to remedy disconnected understanding and disjointed provision to support the many needs of a student. Policymaking is shown to be a corollary of public demands and departmental positions which aims to generate suitable responses or solutions to existing problems within a set of financial and political constraints defined by the immediate context. As opposed to full inclusion, the NSW Government has maintained a strong policy position endorsing a continuum of support services and a parallel school system to achieve middle ground among differential parental demands. The multiple dilemmas circle around dissimilar views and preferences of various stakeholders, consequentially giving rise to a rich hybrid of 'special' education discourses in NSW including integration, inclusion and responses to diversity.

While the Salamanca Statement has gained the endorsement of Australian government, the actual deployment of inclusion into individual states and school settings has progressed to a lesser extent. Unintended exclusion can happen on many grounds, one such example is the incompatibility between national standards and the learning goals of students with a disability which as a result contributes to their exemption from tests like NAPLAN. Within the wider political environment, neo-liberal demands inadvertently work against educational equity through the publication of NAPLAN results, school choice, accountability measures and performative monitoring that substantially raise the stakes of academic competition. In this context, inclusion seems to mainly concern students with additional needs fitting into the wider educational agendas which are of competition and standards. The Australian government has persistently supported school marketization and a strategic performance-based reward system that has widened the social divide instead of mitigating the influence of student background on educational outcomes. The cascade of accountability induced by the federal competitive agenda has aligned NSW Government and its schools to bid for greater academic excellence while inclusion and equity are inadvertently sidelined in policy agenda.

\section{Acknowledgements}

This research is associated with an Australian Research Council Discovery project (Graham, L.J., DP1093020) through sharing interview data of NSW educational policymakers. The research greatly benefitted from the supervision and generous support of Dr Graham who has provided me with insightful feedback. 


\section{References}

Afzal, M., Malik, M.E., Begum, I., Sarwar, K., \& Fatima, H. (2012). Relationship among education, poverty and economic growth in Pakistan: An econometric analysis. Journal of Elementary Education, 22(1), 23-45.

AISNSW Institute (The Association of Independent Schools of NSW). (2017). Diversity and Inclusion: An Overview of Students with Special Needs in NSW Independent Schools. Research Briefing. Retrieved from https://www.aisnsw.edu.au/Governance/Documents/AISNSW\%20Institute\%20 Diversity\%20and\%20Inclusion\%20an.pdf

Andersen, B. (2010). Struggling students 'exempt' from NAPLAN tests. Sydney: ABC News. Retrieved from http://www.abc.net.au/news/2010-05-11/ struggling-students-exempt-from-naplan-tests/430984

Auditor Office of New South Wales (AONSW). (2006). Auditor-General's Report Performance Audit: Educating Primary School Students with Disabilities Department of Education and Training. Sydney: AONSW.

Australian Alliance for Inclusive Education (AAIE). (2018). NSW moves to increase segregation of students with disability. Retrieved from http://allmeansall.org.au/ nsw-moves-increase-segregation-students-disability/

Australian Bureau of Statistics (ABS). (2012). Australian Population Clock [html]. Retrieved from http:// www.abs.gov.au/

Australian Bureau of Statistics (ABS). (2017a). 2016 Census shows growing Aboriginal and Torres Strait Islander population [html]. Retrieved from http://www.abs.gov.au/ausstats/abs@.nsf/ MediaRealesesByCatalogue/02D50FAA9987D6B7CA25814800087E03?OpenDocument

Australian Bureau of Statistics (ABS). (2017b). 6530.0 - Household Expenditure Survey, Australia: Summary of Results, 2015-16 [html]. Retrieved from http://www.abs.gov.au/AUSSTATS/abs@.nsf/ DetailsPage/6530.02015-16?OpenDocument

Australian Government. (2011). Review of funding for Schooling: Final Report. Canberra: DEEWR. Retrieved from http://apo.org.au/system/files/28263/apo-nid28263-52121.pdf

Australian Government. (2018). Through Growth to Achievement: Report of the Review to Achieve Educational Excellence in Australian Schools. Canberra: DEEWR. Retrieved from https://docs. education.gov.au/system/files/doc/other/662684_tgta_accessible_final_0.pdf

Autism Awareness. (2018). Who Can Diagnose. Sydney: Autism Awareness. Retrieved from https://www. autismawareness.com.au/diagnosis/who-can-diagnose/

Bagshaw, E. (2016). NAPLAN 2016: Parent says school asked student to sit out exam. Sydney: The Sydney Morning Herald. Retrieved from www.smh.com.au/national/education/naplan-2016parent-says-school-asked-student-to-sit-out-exam-20160512-got9tu.html

Baker, J. (2018, October 1). NSW government over-funding private schools by $\$ 160$ million. The Sydney Morning Herald. Retrieved from https://www.smh.com.au/national/nsw/nsw-government-overfunding-private-schools-by-160-million-20180928-p506r3.html

Bonnor, C., \& Caro, J. (2007). The Stupid Country: How Australia is dismantling public education. Sydney: The University of New South Wales.

Broomhill, R. (2011). Neoliberal Globalism and the Local State: A Regulation Approach. Journal of Australian Political Economy, 48, 115-140. Retrieved from http://www.rrojasdatabank.info/ neolibstate/jape48.pdf

Chong, P. W., \& Graham, L. J. (2014). Taking a 'Russian doll' approach to international comparative research in education. International Journal of Research \& Method in Education, 36(1), 23-32. doi: 10.1080/1743727X.2012.675555 
Chong, P.W. (2018). The Finnish "Recipe" Towards Inclusion: Concocting Educational Equity, Policy Rigour, and Proactive Support Structures. Scandinavian Journal of Educational Research, 62(4), 501-518. doi: 10.1080/00313831.2016.1258668

Cook, H. (2016). Disabled children shut out of private schools. Melbourne: The Age. Retrieved from http://www.theage.com.au/victoria/disabled-children-shut-out-of-private-schools-20160120gma5f9.html

Dale, R. (2005). Globalisation, Knowledge Economy and Comparative Education. Comparative Education, 41(2), 117-149. doi: 10.1080/03050060500150906

Dempsey, I., \& Foreman, P. (1997). Trends in the Educational Placement of Students with Disabilities in New South Wales. International Journal of Disability, Development and Education, 44(3), 207-216. doi: 10.1080/0156655970440303

Dempsey, I., Foreman, P., \& Jenkinson. (2002). Educational Enrolment of Students with a Disability in New South Wales and Victoria. International Journal of Disability, Development and Education, 49, 31-46. doi: 10.1080/10349120120115316

Department of Education and Training (DET). (1996 - 2011). Annual Report. Sydney: DET. Retrieved from https://www.det.nsw.edu.au/about-us/how-we-operate/annual-reports

Dziedzic, S., Henderson, A., \& Anderson, S. (2016). Gonski: Federal Opposition calls on state Liberal governments to support Labor's education commitment. Sydney: ABC News. Retrieved from http://www.abc.net.au/news/2016-01-29/ liberal-government-support-gonski-commitment-federal-opposition/7122934

Forbes, L. (2012, July). ‘Cold-hearted’ Funding Cuts. Armidale: Fairfax Media.

Gable, A., \& Lingard, B. (2013). NAPLAN and the performance regime in Australian Schooling: A review of the policy context. Research Paper No. 5, Social Policy Unit, University of Queensland, Brisbane.

Gillborn, D., \& Youdell, D. (2000). Rationing Education: Policy, practice, reform, and equity. Buckingham: Open University Press.

Graham L. J., \& Jahnukainen, M. (2011). Wherefore Art Thou, Inclusion? Analysing the development of inclusive education in New South Wales, Finland and Alberta. Journal of Education Policy, 26(2), $263-288$.

Graham, L. J. (2006). Caught in the Net: a Foucaultian interrogation of the incidental effects of limited notions of inclusion. International Journal of Inclusive Education, 10(1), 3-24.

Graham, L. J. (2012). Disproportionate Over-representation of Indigenous Students in New South Wales Government Special Schools. Cambridge Journal of Education, 41(4), 163-176. doi: 10.1080/0305764X.2012.676625

Graham, L. J. (2016). Reconceptualising inclusion as participation: Neoliberal buck-passing or strategic by-passing? Discourse, 37(4), 563-581.

Graham, L. J., \& Sweller, N. (2011). The Inclusion Lottery: who's in and who's out? Tracking inclusion and exclusion in New South Wales government schools. International Journal of Inclusive Education, 15(1), 941-953. doi: 10.1080/13603110903470046

Graham, L. J., Sweller, N., \& Van Bergen, P. (2010). Detaining the Usual Suspects: Charting the use of segregated settings in New South Wales government schools, Australia. Contemporary Issues in Early Childhood, 11(3), 234-248. doi: 10.2304/ciec.2010.11.3.234

Hardy, I. (2013). A logic of appropriation: Enacting national testing (NAPLAN) in Australia. Journal of Education Policy, doi:10.1080/02680939.2013.782425 
Harrington, M. (2011). Australian Government funding for schools explained. Canberra: Commonwealth of Australia. Retrieved from http://www.aph.gov.au/binaries/library/pubs/bn/sp/schoolsfunding. pdf

Hursh, D. (2005). Neo-liberalism, Markets and Accountability: transforming education and undermining democracy in the United States and England. Policy Futures in Education, 3(1), 3-15.

Lingard, B. (2010). Policy Borrowing, Policy Learning: Testing times in Australian schooling. Critical Studies in Education, 51(2), 129-147. doi: 10.1080/17508481003731026

Luke, A. (2010). Will the Australian curriculum up the intellectual ante in primary classrooms? Curriculum Perspectives, 30(3), 59-64.

McGowan, M. (2018, July 6). Private schools on funding 'hitlist' actually increase their funding. The Guardian. Retrieved from https://www.theguardian.com/australia-news/2018/jul/06/ private-schools-on-funding-hitlist-actually-increase-their-funding

McRae, D. (1996). The Integration/Inclusion Feasibility Study. Sydney: NSW Department of School Education.

NSW Department of Education (NSW DoE). (2017). School communities working together. Sydney: NSW DoE. Retrieved from https://education.nsw.gov.au/student-wellbeing/whole-school-approach/ school-communities-working-together

NSW Department of Education (NSW DoE). (2018). Assisting Students with Learning Difficulties. Sydney: NSW DoE. Retrieved from https://education.nsw.gov.au/policy-library/policies/ assisting-students-with-learning-difficulties?type=history

NSW Department of Education and Communities (NSW DEC). (2012). Every Student, Every School: Learning and Support. Sydney: NSW DEC.

NSW Department of Education and Training (DET). (2003). Disability Criteria (school sector). Sydney: NSW DET.

NSW Department of Education and Training (DET). (2006). The Learning Assistance Program: A Reflective Study. Sydney: NSW DET.

NSW Department of Education and Training (DET). (2010). Management of Health and Safety Risks Posed to Schools by Students' Violent Behaviour Guidelines. Sydney: NSW DET.

NSW Government. (2005-2011). Statistics Bulletin. Sydney: Department of Education and Communities: Office of Education. Retrieved from http://www.dec.nsw.gov.au/about-us/statistics-and-research/ key-statistics-and-reports

NSW Government. (2011a). Educational Services Supporting Students with Disability. Sydney: NSW Government.

NSW Government. (2011b). Response to the Report of the Legislative Council General Purpose Standing Committee No. 2: Inquiry into the Provision of Education to Students with a Disability or Special Need. Sydney: NSW Government.

NSW Government. (2016). Enrolments in support classes and schools for specific purposes by category (2011-2016). Sydney: NSW Government. Retrieved from https://data.cese.nsw.gov.au /data/ dataset/enrolments-in-support-classes-and-schools-for-specific-purposes-by-category

NSW Legislative Council. (2010). Government Funding for Students With Disabilities in NSW Private Schools A Submission. Sydney: NSW Legislative Council. Retrieved from www.saveourschools. com.au/file_download/38

NSW Ombudsman. (2013). A Level Playing Field HSC-Disability-provisions. Sydney: Crown Copyright. Retrieved from https://education.nsw.gov.au/teaching-and-learning/disability-learning-andsupport/media/documents/HSC-Disability-provisions.pdf 
NSW Parliament Legislative Council. (2017). Education of students with a disability or special needs in New South Wales, Report no. 37, Portfolio Committee No. 3 - Education. Sydney: Author. Retrieved from https://www.parliament.nsw.gov.au/committees/DBAssets/InquiryReport/ ReportAcrobat/6114/170921\%20-\%20Final\%20report.pdf

NSW Parliament. (2010). NSW Parliamentary Inquiry into the Provision of Education for Students with a Disability or Special Needs. Sydney: NSW Parliamentary Library. Retrieved from https://www.parliament.nsw.gov.au/prod/parlment/committee. nsf/0/32a3f8674373eab6ca2576fe001484e7/\$FILE/Submission\%20259.pdf

People with Disability Australia Incorporated (PWD). (2010). Inquiry into the provision of education to students with a disability or special needs. Sydney: PWD. Retrieved from www.pwd.org.au/ documents/pubs/SB100219InquiryEducation.doc

Polesel, J., Dulfer.N., \& Turnbull, M. (2012). The Experience of Education: the Impacts of High Stakes Testing on School Students and their Families. Sydney: University of Western Sydney.

Powazuk, S. (2013). A Parent's Toolkit School issues for students with disabilities. Retrieved from http://da.org.au/wp-content/uploads/

A-Parents-Toolkit-School-issues-for-students-with-disabilities-v-1.1.pdf

Private Schools Directory. (2018). Catholic and Independent Schools in New South Wales (NSW) and Sydney. Retrieved from https://www.privateschoolsdirectory.com.au/sydney-schools.php

Public Schools Principals Forum (PSPF). (2009). Provision of Services for Special Needs/ Disabled Students in NSW. Sydney: PSPF. Retrieved from www.pspf.com.au/info/ livedocuments/4_693_250.doc

Singhal, P. (2018, April 12). Private schools getting $\$ 6700$ more per student than NSW public schools. The Sydney Morning Herald. Retrieved from https://www.smh.com.au/education /privateschools-6700-student-nsw-public-catholic-20180410-p4z8qn.html

Skidmore, D. (2004). Inclusion: The dynamic of school development. Maidenhead: Open University Press.

Slee, R. (2011). The Irregular School: Exclusion, schooling and inclusive education. London and New York: Routledge.

Strauss, A., \& Corbin, J. (1990). Basics of Qualitative Research: Grounded theory procedures and techniques. Thousand Oaks, CA: Sage.

Talja, S. (1999). Analyzing Qualitative Interview Data: The Discourse Analytic Method. Library \& Information Science Research, 21(4), 459-477.

Taylor, A. (2017, May 26). Principals under pressure to enrol children with disabilities without support. The Sydney Morning Herald. Retrieved from https://www.smh.com.au/national/nsw/principalspressured-to-enrol-children-with-disabilities-without-support-20170525-gwcsbx.html

Tearle, K., \& Spandagou, I. (2012, December). Learning Support Policy in Australia (New South Wales) and New Zealand; Discourses of Influence. Paper presented at the Joint Australian Association for Research in Education and Asia-Pacific Educational Research Association Conference, Sydney.

United Nations Educational, Scientific and Cultural Organization (UNESCO). (1994). The Salamanca Statement and Framework for Action on Special Needs Education. Spain: UNESCO/Ministry of Education: Spain.

United Nations Educational, Scientific and Cultural Organization (UNESCO). (2005). Guidelines for Inclusion: Ensuring Access to Education for All. Paris: UNESCO.

Vickers, M. (2004, October). Education for All Australians: Comprehensiveness, Segregation, and Social Responsibility. Paper presented at the University of Western Sydney Annual Education Conference, Sydney. 
Yin, R. (1994). Case Study Research: Design and methods (2nd ed.). Beverly Hills, CA: Sage Publishing. 